\title{
Investigating the Manifestation of Textual Themes in Argumentative English Assignments Written by Iraqi and Australian Postgraduate Students
}

\author{
Ali Jabbar Al BAKAA (Corresponding author) \\ School of Education, Monash University, Melbourne, Australia \\ PO Box 6, Clayton Campus, Victoria 3800 \\ E-mail: alibka@hotmail.com
}

Received: 04-06-2014

Accepted: 27-07-2014

Published: 01-11-2014

doi:10.7575/aiac.ijalel.v.3n.6p.205

URL: http://dx.doi.org/10.7575/aiac.ijalel.v.3n.6p.205

\begin{abstract}
This study investigated the manifestation of Textual Themes in argumentative English assignments written by Iraqi and Australian postgraduate students. Textual structure is a core component of argumentation in academic writing. How the themes in a text are organized as a message component constructs voice and authority. An important question is how novice writers and in particular international students are able to handle these textual devices when they write their English academic assignments. To this end, four academic assignments were selected and analysed to uncover the similarities and differences in textual features, and how students of different cultures stamp their authorial voice on the text through the element of theme and rheme in their academic arguments. The data were analysed based on Halliday's (2004) model of thematic organization. The findings showed that the failure to use theme appropriately in constructing a voice and authority in academic writing may have disadvantaged the non-native writers. The paper argues that this has occurred because critical thinking requires a clear self-voice in forming an academic argument. This has not been explicitly emphasized in the writers' Iraqi curriculum for writing. In contrast, these elements are more explicitly emphasized in the Australian writing curriculum.
\end{abstract}

Keywords: English academic assignments; Iraqi non-native writers; Australian native writers; textual structure; voice and authority; thematic organization; critical thinking

\section{Introduction}

Assignments are generally defined as an important component of study at western universities. They usually consist of a few thousand words discussing a topic of study at both undergraduate and postgraduate levels. Academic assignments require the students to be familiar with requirements such as critical thinking and to express this within the textual structures, which are the ways in which information is organised by such features as sequencing, topic sentences, and cause and effect markers to form academic arguments. These features are realized through the linguistic systems of theme/ rheme and cohesion (Halliday \& Hasan, 1976).

Based on the work of Halliday and Hasan (1976), clauses in English texts typically begin with something that is familiar or already known to the reader (the theme) and then move on to present something new (the rheme). Cohesion refers to the way a text hangs together with the help of linguistic devices such as pronouns (e.g., it, this, we), and conjunctions (e.g., although, above all, for example, therefore, meanwhile, but). Analysis of the theme/rheme structure helps us see how a text is organized and how information flows in a text. Thus, this study investigates the relationship between textual themes and the author's critical stance in formulating good arguments in English academic assignments.

\section{Previous Studies in Academic Writing: Expectations and Requirements}

What is required and expected in academic writing at Australian universities has been the concern of many academic researchers. Moodie (2001) pointed out that "if international students come from educational systems and cultural backgrounds" where it is difficult to question the views and validity of other respected authorities, it will be difficult for them to express their voice critically, which is the requirement of Western academic communities (p. 2). In the same vein, Sinclair (2000) stated that many international students from non-English speaking backgrounds (NESB) at Australian universities are confused by differences in the teaching styles and expectations of their own learning, and what is required from them in terms of academic assignments, all of which place emphasis upon learner independence. Sinclair (2000) further concluded that there is no question about the usefulness of critical thinking in forming academic arguments. However, to critically evaluate the work of others, academic writers are required to provide an argument of their own in relation to other researchers, which in turn makes their own academic work critically effective and persuasive to their reader. If postgraduate students are not equipped with the element of critical thinking -which is the requirement of academic work- it would be difficult for them to position themselves in relation to the work of others, 
which in turn makes their written work purely descriptive as they defer to the words and opinions of other writers.

Along the same lines, Farrell (1997, as cited in Phan Le Ha, 2009) stated that the requirements of academic writing in English speaking countries expected the writers to use "highly specialised discourse, and be objective, and sequential" (p. 135). Phan Le Ha (2009) argued convincingly that candidates at Australian universities are required to show their ability to think critically in an English academic writing style. Moodie (2001) pointed out that international postgraduate students' lack of familiarity with the expectations of their new discourse communities "makes it particularly difficult for them to write reviews of the literature where they need to express critical evaluations and to make appeals to values shared with their readers" (p. 1).

\section{Textual themes as a critical stance in academic writing}

In cross cultural studies of academic writing, Wang (2007), for instance, explored the relationship between theme and rheme organization in texts written by sophomores majoring in politics from a South-Eastern University in China. The results showed that "students' weaknesses in their argument were due to problems with - thematic development in their written texts" (p. 174). Moreover, the lack of thematic development made their written text read "like a list" as there was a "lack of further development in the rheme" (p.171). This study has also shown that this is the characteristic of descriptive and narrative texts, which use a constant progression pattern, while in an "argumentative text" there is need of "cross-referential links from the rheme element of one clause to the theme of the next clause" (p. 171).

Mellos (2011) analysed the textual themes in eight undergraduate ESL students' essays, four of which were evaluated as high in coherence and four of which scored low in this respect. The goal was to explore whether the theme and rheme pattern choices can achieve coherence in academic writing. The results showed that the essays scoring high on coherence employed a wide variety of textual themes to establish connections between different parts of the text commenting on abstract ideas relevant to the topic. In contrast, low ones employed overuse of unmarked themes in a way that makes the text difficult to follow by the reader. Jalilifar (2010) in a study of textual themes, as a way to improve coherence in writing, examined thematic types in different rhetorical sections of international and local journals, and generated similar findings to those of Mellos (2011).

Ebrahimi (2012) investigated the incidence of textual themes in academic reading texts, comparing native and nonnative writers of English. Sixteen texts from four academic reading textbooks were selected for the purpose of investigating the frequency of textual theme and its functions. The results showed that textual theme and its types were distributed differently in texts written by native and non-native writers. The results reported that textual theme was the highest frequency element in native writers' work compared to non-native writers. Native writers used more structured theme patterns to provide more explicit guidance to the reader on how to (re)construct a coherent text, and created semantic and structural relationships between the sentences in the texts. They used a variety of textual themes and more conjunctions, coordinators and subordinators to carry out the internal and external functions of textual theme and to create more cohesive text. The internal function is to give organized information and the external is to express logical relations to hold the text together. While non-native writers' textual themes were realized through themes such as and, and but, native writers used multiple words for comparison such as however; therefore; or; so; even; and, also.

Providing effective arguments, which are required and expected by readers, might be challenging for Iraqi postgraduate students. Elsegood (2007) pointed out that in Western academic writing people are encouraged from an early age to evaluate the ideas of others by making and supporting personal judgments about a specific topic. Evaluating something means making and supporting a judgment. He also stated that Westerners, including children, are expected to engage in "rigorously defending personal positions" and critically demolishing other views by giving logical reasons (p. 3). Such expression of a defensible position requires a strong voice that carries the authority of a reasoned argument and takes responsibility for this argument. This valuing of personal reasoned argument suggests that writing skills are developed in native writers as a result of the acculturation and the social integration into the group using the target discourse, whereas it would be difficult for those who had less integration with the culture of the target language and discourse community. Certainly, given the focus on acceptance of 'knowledge' in Iraqi education, Iraqi students may stumble over these specific features in writing, not because of lack such voice and Authority in Arabic, but because the curriculum does not prepare them for this.

Taking the importance of textual theme structure as denoting voice and authority in formulating arguments in students' academic writing, this study attempted to investigate similarities and differences in the ways some Iraqi and Australian postgraduate writers formulate arguments according to the expectations of readers in a comparable assignment, in order to identify areas for improvement. This study provides a descriptive and explanatory analysis of the nature of these writers' performance in their English academic assignments, based on the texts they produced.

\section{Method}

\subsection{Corpus}

The study focused on the corpus of four academic assignments written for the course of Masters of TESOL by native (Australian) and non-native (Iraqi) writers of English to compare the similarities and the differences through the functional analysis of textual themes. One segment on the same topic has been chosen across these assignments for the basis of comparison.

Segments A1 and A 2 were written by Australian postgraduate students who are native writers of English;

Segments Ir 1 and Ir 2 were written by Iraqi postgraduates who are non-native writers of English. 
The data came from assignments written for the unit "Language, society and cultural differences" in the Master of Education (TESOL) at Monash University. Upon the successful completion of this course, the students are expected to understand and reflect critically on the core principles of language learning, so as to develop sound pedagogy with strong theoretical foundations, which can be adapted and applied to particular international contexts. The unit is a fundamental critical unit in the course. It aims to develop the capacity of self-directed learner-researchers in the classes and on-line activities to explore the ways that language, society, and cultural difference are related to each other, and why this matters to educators working in schools, universities and technical colleges (Faculty of Education, 2013). It has been designed to cover topics around language, culture, identity, and differences; English language education in local (Australian), and global contexts, and the political and social implications of the globalisation of English in issues related to immigration and cultural difference in multiple contexts (Faculty of Education, 2013).

The unit is divided into three sections. The first section is concerned with the ideas of language, cultural and political practices. In this particular section the students are required to use Hall's notion of representation in order to understand language and cultural difference by giving examples from their own experience. In this task, students have to demonstrate a critical understanding of the complexities of Hall's argument. In the second section, the unit extends its readings to discuss the aspect of identity within language learning and teaching. Recent debates of English as an international language are also discussed in this unit, including issues raised by significant scholars such as Kramsch, (1998), Pierce (1995), Canagarajah (1999), and Phan (2008). The third section of the unit debates issues related to language policy, curriculum and pedagogy in Australian and overseas contexts. Studying this particular unit, students are expected to express their authorial voice, and critical thinking to form good academic assignments.

\section{Analytical Model}

In this study, Halliday's (2004) analytical model of thematic organization was used to investigate the features of the textual structure of the academic assignments. The rationale for the selection of Halliday's model was that this model is the most plausible and has been recently updated. In this research, the theme types were analysed at the level of clause rather than at the sentence level because the research aimed to identify similarities and differences in the way thematic structures across small segments of the academic assignments are employed (Eggins, 2004). According to Halliday textual themes include items such as:

A. Continuative item which are defined as a small set of discourse items which signal that a new move is

Example (1): Student A 1: Another way of viewing identity emerges from a post-structural (Norton-pierce 1995, p. 16) approach acknowledging that a group or community may have a lot in common as well as 'critical point of deep and significant difference which constitute "what we really are" (Hall, 1997, p. 52).

B. Structural elements like coordinates and subordinates (Example 2).

Example (2): Student A 2: From a cultural point of view, Identity is not only a product of the past, but exists in the future.

C. Conjunctive adjuncts relate one clause to the preceding text such as that is, for instance, in short, also, but, however, then, yet, rather (Example 3).

Example (3): Student A 2: Beholding people to slot themselves within certain identities maintains cultural practices and thus a sense of shared experience, yet this alone does not appear to be a satisfactory way to understand identity in relation to culture.

\subsection{Unite of Analysis}

To analyse the data, t-unit was selected. T-unit is defined by Fries (1994, p. 318, as cited in Ebrahimi, 2012, p.259) "as a clause complex which contains one main independent clause together with all the hypotactic clauses which are dependent on it" (p. 318). The rationale behind this selection was that: Analysing theme at the level of t-unit rather than the individual clauses make it easier to focus on patterns of the thematic development in large amounts of text, and can also be justified on the grounds that the thematic structure of a dependent clause is often constrained by the independent clause" Fries \& Francis, 1992 as cited in Ebrahimi, 2012, p. 91).

\subsection{Procedure}

After, the four academic assignments were collected, the data were analysed based on Halliday's (2004) categorization of textual theme and its types. The frequency of textual theme types in these academic segments was calculated. Finally the differences and similarities in the frequency were discussed. One problem in discourse analysis is the danger of making mistakes in the data analysis and interpretations (Ebrahimi \& Ebrahimi, 2012). Therefore, to increase the reliability in this current study, one segment of each group was also analysed by an experienced researcher in applied linguistics. 


\subsection{Selection of the Participants}

There were two main criteria in the process of the participant selection. The Iraqi participants must not have been educated in English-speaking or Western countries prior to their enrolment in the Australian Masters, and must have completed their first assignment for the unit within the year 2012. The Australian participants, in contrast, must not have been educated in Iraq or similar countries prior to their enrolment in the Australian Masters, and also needed to have completed their first assignment for the unit within the same year.

\section{Results and Discussion}

To uncover the frequency of the textual themes as a message component in the construction of voice and authority in the participans' texts, segments of these academic assignments were analysed based on Halliday's (2004) model of thematic organization. The results are presented in Table 1, which indicates that the Australian native writers of English used textual themes $(27 \%)$ slightly more than the Iraqi non-native writers $(22 \%)$. The textual themes and their types were tackled differently by these two groups.

Table 1. Frequency of textual theme functions in the students' written segments

\begin{tabular}{lccrc}
\hline Textual theme & Student A 1 & Student A 2 & Student Ir 1 & Student Ir 2 \\
\hline Textual (TX) & $10(27 \%)$ & $4(5 \%)$ & $7(22 \%)$ & $3(21 \%)$ \\
\hline Total (in whole piece) & $37(100 \%)$ & $19(100 \%)$ & $32(100 \%)$ & $14(100 \%)$ \\
\hline
\end{tabular}

\subsection{Textual features found in the argumentative writing of Australians writers}

These Australian writers tended to employ a variety of effective textual themes and multi-word expressions to signal an additive relationship to link their sentence sequences: for instance, furthermore, even though, however, through this, in addition, this, yet, through. This suggests that these writers took pains to tell their reader when their message in their text was critically contrary to the previous message, or that it had an additional meaning. This in turn provided the textual voice that spoke between clauses and offered interpersonal assistance for their readers. Examples 1, 2, 3 and 4 show the writer's stance as they used different functions of textual themes in their written segments.

Example (1) Student A 2

\begin{tabular}{ll}
\hline Textual theme, Ideational theme & \multicolumn{1}{c}{ Rheme } \\
\hline Furthermore, people $<\mathrm{UM}>$ & $\begin{array}{l}\text { are increasingly choosing/forced to live outside of their } \\
\text { birthplace for a number of reasons. }\end{array}$ \\
\hline
\end{tabular}

Example (2) Student A 2

\begin{tabular}{ll}
\hline Textual theme, Ideational theme & \multicolumn{1}{c}{ Rheme } \\
\hline Even though, this understanding of identity $<\mathrm{UM}>$ & is commonly referred to as being essentialised \\
it $<\mathrm{UM}>$ & is an imaginary creation, not an essence captured from the pas1 \\
& (Woodward,1997). \\
\hline
\end{tabular}

Example (3) Student A 1

\begin{tabular}{ll}
\hline Ideational theme & \multicolumn{1}{c}{ Rheme } \\
\hline Beholding people $<$ UM $>$ & to slot themselves within certain identities maintains cultural \\
& practices and thus a sense of shared experience. \\
alone does not appear to be a satisfactory way to understand & identity in relation to culture. \\
\hline
\end{tabular}

Example (4) Student A 1

\begin{tabular}{ll}
\hline Marked theme & \multicolumn{1}{c}{ Rheme } \\
\hline Through this lens $<$ MT $>$ & the individual cannot deny particular aspects of themes but \\
& $\begin{array}{l}\text { alongside this also have self-determination to choose parts of } \\
\text { their identity. }\end{array}$ \\
\hline
\end{tabular}

These various textual themes functions display how A1, A2 stamp their personal authority by using more comparison and build up different layers of their critical analytical arguments. These writers present their viewpoints on text critically through these variously developed textual themes for their topic. These complexities of textual theme patterns have been used by these Australian writers to persuade their reader to either agree or disagree with their opinion on that particular topic of writing. It seems, they had a strong academic sense that to persuade their reader, they needed to build up a strong critical argument, and this would not occur without stamping their authorial voice clearly on text through 
these different features of textual themes. As skilled writers, these students have not relied on content words or only one academic dimension; rather, they used a wider range of resources with a complex discourse to put their critical ideas forwards to their reader. In the case of Student A2, she uses the authority of other ideas to give authority to her own ideas. So, she gives facts and re-organizes them using other different views. Student A 2's point of view focuses on dimensions which she justifies with other articles, thus she links her views to those of other authors, which results in a critical argument. This is how she marshals a critical analytical argument in her written segment on the identity aspect. She has added her view to Hall's views (mentioned prior to the analysed segment) and has not relied only on Hall's idea in forming her argument. So, her voice is clear and visible and offers a personal and political agenda to her reader.

Another interpretation is that since Westerners are encouraged from an early age to evaluate the ideas of others by making and supporting personal judgments about a specific topic, they are able to provide critical and interpretive arguments rather than only descriptive ones. This suggests why these Australian native writers are critical thinkers and authoritative in their written academic segments. The aspect of critical thinking and self-voice through use of multiple voice in forming their academic arguments is explicitly embedded within their Australian education system, and as a result of this, these native writers' prior educational experiences have provided a facilitating tool for generating strong and authoritative academic arguments. These findings are in line with those from previous research, which has shown that Westerners, including children, are expected to engage in "rigorously defending personal positions" and critically demolishing other views by logical reasoning (Elsegood, 2007, p. 3), and is consistent with the studies of Phan (2009), who argued that in Australian universities writers are required to show the element of critical thinking and voice, and questioning, discussing their ideas in a logical and visible way. Furthermore, the Australian native writers' participants used more subordinate clauses to make the critical engagements function. These results are in line with those of Ebrahimi and Ebrahimi (2012) who found that native writers of English used more textual theme patterns in their academic texts to provide more explicit guidance to their reader on how to construct a coherent interpretation of their text (p. 259).

\subsection{Textual features found in the argumentative writing of the Iraqi writers}

In contrast, the frequent repetition of unmarked ideational themes used by the Iraqi students and the low frequency of a variety of textual themes suggest that the connectivity between their ideas does not develop a clear critical argument; rather, it makes their text descriptive. In the descriptive and narrative text segments, the Iraqi writers tend to list information descriptively without positioning themselves in relation to authorities and other writers. This usually happens when writers repeats the use of one clause such as "unmarked ideational themes" into the theme of the subsequent clause without having high incidence of cross referential links forming the rheme of one clause into the theme of next clause. A possible justification for the more numerous occurrences of the unmarked ideational themes patterns is that these Iraqi students have probably never been told how to write argumentative assignments within their Iraqi education system and are thus not aware of how to positioning their authorial voice through the textual structural. This lack of experiences or unfamiliarity of these students with persuasive discourse has been identified in this study as being one of the main reasons for not being able to position themselves in objective academic texts.

These Iraqi students should understand that using unmarked themes in terms of personal names in large numbers in their writing would not help them to develop their ideas; rather, than it can bury their authorial voice, preventing it from being visible through the element of theme and rheme. They also need to keep in mind that using a variety of textual themes could contribute the development of a complex argument with a highly authorial voice in their text. This high incidence of unmarked themes in the Iraqi postgraduate students is exemplified by the writing of Student Ir 2, who mostly employed personal names in the unmarked theme stems. They showed the characteristic of spoken discourse in using limited conjunctions to link the sequences of the sentences.

Example (5) Student Ir 2

\begin{tabular}{ll}
\hline Unmarked theme & \multicolumn{1}{c}{ Rheme } \\
\hline Hall $(1997)$ argues that cultural identity $<\mathrm{UM}>$ & is represented through producing and exchanging meanings. \\
Hall $<\mathrm{UM}>$ & proposed the term of "Diaspora " to refer to any migrants people \\
& that share common ethnic identity such as the African Diaspora \\
& in Europe \\
Hall $<\mathrm{UM}>$ & refers to this diaspora and mentions that all cultural practices and \\
& forms of representation are putting the issue of cultural identity \\
& in question of" who is this emergent" (p. 392). \\
\hline
\end{tabular}

Even though there are limited conjunctions in these written segments (e.g. in this light, additionally, to summarise), these occur between paragraphs and not between sentences, which would have helped the reader to follow the organization of the surrounding segments. These findings are in agreement with what has been confirmed by Ebrahimi and Ebrahimi (2012), namely, that texts written by non-native writers are mostly realized through simple functions of textual themes such as and, and but, in contrast with native writers who use the highly effective technique of textual theme patterns to enhance the connectivity of their ideas in "semantically and structurally" suitable ways (p. 260). The low incidence of variety in textual theme functions in the Iraqi postgraduate students' writing is exemplified by Student Ir 1, who employed mostly limited textual themes in the written segments. 


\begin{tabular}{ll}
\hline Textual theme/ conjunctive & \multicolumn{1}{c}{ Rheme } \\
\hline To summarise, Hall $(1997)<\mathrm{UM}>$ & $\begin{array}{l}\text { suggests that cultural identity supplies a relation between } \\
\text { individuals and other people. }\end{array}$ \\
Additionally, Hall $<\mathrm{UM}>$ & $\begin{array}{l}\text { refers to the idea that identity is not as transparent or } \\
\text { unproblematic as we think" (p. 1). }\end{array}$ \\
\hline
\end{tabular}

In short, the higher frequency of the textual themes in the Australian native writers' written segments than those applied by the Iraqi postgraduate non-native writers of English indicates the higher authoritativeness of the native writers, as well as providing internal and external cohesion in expressing logical relations to hold their text together. Australian native writers of English displayed the textual features of expository writing rather than narrative, in that they provided an initial overview to their structure of their segments. The Iraqi non-native writers in their segments however, did not show the features of expository writing; rather they engaged in a narrative by 'telling' their readers in fully descriptive details. More specifically, the Iraqi students have not put their own viewpoint but simply borrowed somebody else's viewpoint into their academic writing, and as a result of this, their argument has suffered from weaknesses in expressing the authorial voice effectively in the Australian context of writing. In their case, the high incidence of unmarked theme, and low variety of textual themes made their stance descriptive rather than argumentative.

These results may indicate why the Iraqi postgraduate students could not integrate their textual voice as a stance to express their own ideas. This could be for two reasons: one is that in Iraqi EFL teaching settings, Iraqi EFL teachers are highly appreciated and students are not encouraged to show their agreement and disagreement about the topics they are discussing. This results in their weakness in expressing their original ideas critically by using their self-voice in their writing. The second reason for this lack of critical thinking and self-voice in their writing. might be because these elements have not been explicitly taught in their education system, which is comparable with previous studies (Alagozlu, 2007; Barnawi, 2011), and with work by Moodie (2001) whose study indicated that lack of familiarity with the expectations of their new discourse communities "makes it particularly difficult for international postgraduate students to write reviews of the literature where they need to express critical evaluations" (p. 1).

\section{Conclusion}

The data analysis indicated differences in the functional use of textual themes in forming academic arguments. Overall, successful segments by the native writers introduced personal judgment in the theme position stems and linked that judgment with the other sentences in an effective and consistent way. Moreover, the Australian native written segments structures concentrated on the entire text and its overall coherence in relationships between and within sentences.

On the other hand, the Iraqi postgraduate non-native writers tended to repeat the nominal subject as theme instead of using an internal textual theme to linked the sentences in that segment to build up a sense of clarification of focus. These Iraqi non-native writers focused mostly on word and sentences level structures in their writing rather than on structures at the level of their whole written discourse. This difference between the two groups indicates that segments developed by Iraqi postgraduate students were not argumentative but rather descriptive. This implies that critical thinking is valued differently in different cultural and socio-political contexts.

The result of this study will benefit teachers of English as a foreign language in Iraqi contexts as they consider how best to introduce the nature of English academic assignments and related strategies to students wishing to study overseas. As well, it will benefit the Iraqi English language students in teaching the critical thinking elements in writing in Iraq. In turn this will help Iraqi postgraduate students to be fully equipped with the standards of Western and Eastern academic writing requirements, and increase the familiarity with the specific genre as a global requirement for writing. All this will help them to become effective academic writers using discourse strategies like those of native speakers when it is appropriate to do so. Finally, the study reflected the differences of writing strategies between the Australian and the Iraqi culture without the intention of imposing one strategy or valuing one over the other.

\section{References}

Alagozlu, N. (2007). Critical thinking and voice in EFL writing. The Asian EFL Journal, 2, 118-136

Barnawi, Z. (2011). Finding a place for critical thinking and self-voice in college English as a foreign language writing classrooms. English Language Teaching, 2(4), 190-197.

Ebrahimi, S., F. Ebrahimi, S., J. (2012). Point of departure in texts developed by native and non-native writers. Language in India, 12, (5), 1-5.

Elsegood, S., (2007) Teaching critical thinking in an English for academic purpose program using a 'claims and supports' approach. First Year in Higher Education Conference, 1, 1-10.

Eggins, S. (2004). An introduction to systemic functional linguistics. London, England: Continuum.

Faculty of Education, Monash University (2013). Unit guide EDF 6236. Melbourne: Faculty of Education, Monash University. 
Halliday, M. A. K. (1976). An introduction to functional grammar. London: Edward Arnold.

Halliday, M.A.K. (2004). An introduction to functional grammar (3rd ed.), London: Edward Arnold.

Jalilifar, A. (2009). Thematic development in English and translated academic texts, Journal of Language \& Translation, 10,(1), 81-111.

Jalilifar, A. R. (2010). The status of Theme in applied linguistic articles. The Asian ESP Journal, 6(2), 7-38.

Mellos, V. (2011). Coherence in English as a second language undergraduate writing: A theme-rheme analysis. (Unpublished master's thesis) San Diego State University, USA.

Moodie, J. (2001). The development of critical voice in the writing of international postgraduate students. Changing Identities, national Language and Academic skills Conference, Wollongong, 28, 1-7.

Phan, Le Ha (2009). Strategic, passionate, but academic: Am I allowed in my writing?. Journal of English for Academic Purposes, 8, 13-146.

Sinclair, S. (2000). When I say 'Describe' I don't mean that you should just describe'....in Sources of Confusion, National Language and Academic Skills Conference, La Trobe University, 11, 304-312.

Wang, L. (2007). Theme and rheme in the thematic organization of text: Implications for teaching academic writing. The Asian EFL Journal, 9, (1), 164-176. 